\title{
Public Sustainable Development Values: A Case Study in Sepang, Malaysia
}

\author{
Zurina Mahadi (Corresponding author) \\ Centre for General Studies, National University of Malaysia \\ 43600 UKM Bangi, Selangor, Malaysia \\ Tel: 60-17-394-8614Ｅ-mail: kina@ukm.my
}

Abdul Samad Abdul Hadi

Institute for Development and Environment, National University of Malaysia 43600 UKM Bangi, Selangor, Malaysia

Tel: 60-3-8926-1236Ｅ-mail: asamad@ukm.my

Hukil Sino

Faculty of Allied Sciences, National University of Malaysia

50300 Kuala Lumpur, Malaysia

Tel: 60-17-325-0143Ｅ-mail: hukil@fskb.ukm.my

Received: November 29, 2010

Accepted: December 17, 2010

doi:10.5539/jsd.v4n2p154

This research is funded by Fundamental Research Grant Scheme (UKM-11JC-04-FRGS 0003-2006), Department of Higher Education, Ministry of Higher Education, Malaysia.

\begin{abstract}
The continuous process of observing and assessing the development scenarios around them provide the public the perception and understanding of the current development issues. The shortcomings of the current development methods inspire the public to develop a set of preferred development values. The information of public's development values is important to sustainable development management as values underlie people's action and behaviour. Without greater understanding and awareness of this, conflicts over management are prone to occur. This research focuses on the development values from the socio-cultural point of views in Sepang, Malaysia. Using qualitative methods, in-depth interviews and group discussions of selected respondents were held to represent their views and communities represented by them. The analysis of data highlights five theme values in development namely identities, peace, freedom, environment and development. There were seven fundamental needs according to Max-Neef list evident i.e. subsistence, protection, affection, participation, creation, identity and freedom.
\end{abstract}

Keywords: Values, Needs, Well-being, Sustainable development

\section{Introduction}

Values are enduring concept of worth; they are formed out of social process of dialogue and debate and influenced by the social, cultural, historical and geographical relationships between society and individual. They are constructed between individuals and institutions and are informed by ethical and moral judgments and by creating priorities in ideas and belief systems. According to O'Brien and Guerrier (1995) they are the reasons we give for justifying proper conduct. The research tradition outlined by M.Rokeach and S.H.Schwartz treat values as a special kind of beliefs-those that organize other beliefs. Rokeach (1973) defined values as guiding principles in the life of an individual or a group. Compared to attitudes, values are more general and enduring - they transcend specific situations, and may be conceptualized as attitudes towards abstract goals of human activities. Schwartz, who elaborate Rokeach's value model, has given different definitions of values; "values are cognitive/social representations of the important goals of motivations (biological, social interaction and social 
institutional needs)" (Prince-Gibson \& Schwartz 1998), values are "broad-qualities that underlie and justify attitudes and behaviour"; "values set goals that represent individual or collective interests" (Schwartz \& Sagiv 1995), values are "socially approved verbal representations of basic motivations" (Sagiv \& Schwartz 2000). Referring to the social-level values, Schwartz define values as a particular interrelated set of values, used for expression, maintenance and justification of a particular cultural strategy" (Schwartz \& Bardi 1997).

Development values, as covered by early literature focused on economic development including employment, consumerism and gross national product (GNP). More recently, attention has also focused on human development (for example values of health, education and equity) and finally, the focus was shifted to human development which emphasizing on the security and well-being of nation-states, regions and institutions. Sustainable development which has emerged out to reconcile the competing demands of development and environmental protection beginning with the 1972 Stockholm Conference on the Human Environment (Adams, 1990) also endorse its sets of values to manoeuvre the concept. Environmental protection and development remain to be the key values of sustainable development (World Commission on Environment and Development, 1987) until today. These values resemble the continuum of the collective aspirations of the world's peoples following World War II: peace, freedom, development and environment (National Research Council, 1999). Departing from the reinforced pillars of sustainable development; economic development, social development and environmental protection, sustainable developments values have evolved at local, national, regional and global levels (The Johannesburg Declaration on Sustainable Development, 2002).

Values play significant roles in navigating the social pillar of sustainable development as they are of central importance in people's lives (O'Brien, 2005) and affect people's action and behaviour. Milbrath (1984) argues that assuming or underestimating the values people hold would cripple development process since it could lead into multiple policy disagreements Clarification and information on the values that people hold for development could provide direction for policy-makers in trying to find solutions to current problems and to advance development policy and management. For the time being, sustainable development values have been, and still being identified, verified and justified at the governance level but their congruent with the actual values behold by the local public are still in question. This study is undertaken to explore, comprehend and provide greater understanding of the values publics have for sustainable development from both urban and rural perspectives.

\section{Research method}

A qualitative methodology was used for this research.

\subsection{Research framework}

Sustainable development is a concept that addresses societal development, judging it on its capacity to meet individual needs now and in the future. Defined as development that meets the needs of the present without compromising the ability of future generations to meet their own needs (World Commission on Environment and Development, 1987), it contains within two key concepts; the concepts of 'needs' in particular the essential needs; and the concept of limitations imposed by the state of technology and social organization on the environment's ability to meet present and future needs (World Commission on Environment and Development, 1987). So from the beginning, sustainable development was defined through its capacity to meet human needs. The essential needs within the Brundtland are believed to be covered by subsistence according to Max-Neef (see Max-Neef et al, 1991) fundamental needs theory. The eight other fundamental human needs in Max-Neef's concept are not directly by the Brundtland definition but related to improving the human well-being. Well-being, as defined by Dolan, Peasgood and White (2006) refers to fulfilment of needs.

Therefore, incorporating the Max-Neef's fundamental needs theory into the Brundtland definition, we define sustainable development needs as, “...the needs in development to be satiated to secure the well-being of human and its supporting systems". There are two ways to incorporate needs into values; first, as needs are determined and defined by values therefore the needs components can be looked upon as the systematic reflection of public sustainable development values; second, in many circumstances, the value become a need (for example freedom) therefore the needs can also directly treated as value, and can be used exchangeable. In this research, needs would be seen as both direct and indirect type of values. We will identify the needs and well-being component by looking into the respondents' expressions of dissatisfaction their expectations towards current development, and their aspiration of future development. We will also be watching for the elements of believes, principles, representations of goals, qualities and interests in the expressions as they are the many forms of values.

Towards the synthesis, Schwartz theory of values will be partly referred along with the views by other researchers of this subject. 


\subsection{Research area}

Sepang, Malaysia is selected as the research area due to the rapid development process which has transformed this previously an agriculture based, rural areas to semi-urban and urban areas. The scenario is resulted from the development of Kuala Lumpur International Airport (KLIA) and W.P. Putrajaya as the central government administration centre in Sepang. The operation of KLIA is fully supported by highly upgraded infrastructures and highways linking it to the major trading points (e.g. Klang Port) and Kuala Lumpur, the capital city of Malaysia.

Sepang was previously an agriculture based area where rubber and palm plantation were the major commodities. In 2005, approximately 46.37 percent of total area was designated for agriculture activities (a deficit of 96.56 percent of total agriculture area in 2002). This tremendous depreciation indicating the major transformation Sepang is experiencing in recent years.

The public in Sepang can be divided into the rural and urban communities. The rural communities reside in nineteen traditional villages in Sepang which is lead by the villages' heads. The village heads play the main role as the representative or spokesperson of the rural communities and act as the mediator between the communities and the government. The urban communities are represented by Council members, whom were appointed by the Municipal Council. The increasing urban area has been divided into 23 zones (increment of 10 from 13 zones in the previous year) to allow effective and systematic governance. Each zone is represented by a council member.

\subsection{Sampling method and approach}

A qualitative methodology was used with the collection of data through a series of in-depth interviews and discussion groups (Figure 1). Qualitative social research focuses on obtaining in-depth understandings of the meanings and definitions people give to their lives in order to understand people's actions and behaviour (Williams and May, 1996; Tesch, 1990). The importance of qualitative approaches is that they can provide insights into the meanings of the responses people give to questions asked of them and also offer insights into why they respond as they do in particular situations (O'Neill, 2001).

We conducted interviews with the former and present Municipal Council members to represent the urban communities' views. We also conducted two in-depth discussion groups with the former and presents villages heads to gather the development values of their own and the villagers represented by them. The rural communities' perspectives are very important because they are likely become the most affected component in the development process. We decided on group discussion mode of values eliciting for the rural communities because of their limited knowledge upon sustainable development concept.

\subsection{Data analysis}

We decided to analyse the interviews and group discussion using thematic analysis to explore the main perspectives of the topic studied (Figure 1). Once the data have been collected, the aim was to develop and carry out a thematic analysis of the major perspectives of public's concern on development. Thematic analysis involves methodically reading through the verbatim transcripts and segmenting and coding the text into categories that highlights what the group discussed (Boyatzis, 1998; Aronson, 1994). The categories were derived from the issues raised by the respondents. They were then assessed, compared and interpreted and any similarities and differences were noted between. The categories were combined and assigned to major themes that provide a framework to explain how public values the development in their area. In this study, each issue secure the needs of the respondents which initially indicate their sustainable development values. We conducted the interpretivism approach to grasp the insight of respondents' development values formation.

\section{Research themes}

Five major themes emerged from the results i.e. identities, peace, freedom, development and environment (Figure 2). The themes provide a framework in which the values form and circulate in the development process. In this study, the themes resemble the respondents' theme values because they reconciled their needs upon valuation and reflection of pursued values.

\subsection{Identity}

There was widespread believe among the respondents that the solidarity of local culture and tradition is loosening due to foreign and outside influence. Three major sources of foreign influences drawn by the respondents were foreign students and workers (of construction and manufacturing sectors), property purchasers and tourists. The numbers of foreign students (domineer by the Africa and China origins) in this area have increases significantly due to the rapid development of private colleges and universities here and in adjacent area. 
The population of foreign workers becoming larger due to development of multi mega projects like KLIA, Cyberjaya and Putrajaya. There were increasing incidents of social deviant related to foreign students and workers in recent years. The students frequently reported to be heavily involved in drugs and alcohol which will likely ignite precarious consequences. The respondents particularly worried that the local people especially younger generations will adapt these unacceptable behaviours which might lead to destruction of identity. The workers on the other hand, are claimed to be responsible for the rising incidents of illegal abortion resulted from their relationship among themselves and with local females. These workers mostly come from Indonesia, Myanmar, Vietnam, China, Bangladesh and Pakistan. The respondents were very uncomfortable with this scenario which they truly believed could deteriorate the identity crisis further. Therefore they demand the authority to enforce measures to mitigate this problem. Furthermore, they urged the community to participate by continuously monitoring and reporting every related incident in their area.

The other channels of foreign influence identified by the respondents in Sepang are through property purchasing and tourism. In present development, the government ease the procedure and predicament in property buying to enhance foreign investment and this has successfully attracts the foreigners and outsiders to purchase properties in this area. According to the respondents, by owning a property and staying, the foreigners will likely able to penetrate deeper into local social setting. The home-stay concept of tourism also demonstrates similar implication. Due to the longer period of staying in proximity, these modes of tourism and accommodations will likely offer effective transferring of foreign norms to locals. Such invasion is seen as a powerful threat to local norms and identity. To aggravate the impacts further, the local tourism promoters at Pantai Bagan Lalang Sepang are claimed to adopt foreign tourism programmes to attract the foreign tourist whereas they should promote local values. The respondents strongly feel that any programs and celebrations regarding tourism should only be approved by the authority when they comply with local values under the consent of local community.

Besides foreign influences, the respondents also identified several local causes of identity disruption which were demonstrated in four scenarios below. First are the outsiders whom reside in individual properties all over Sepang. The respondents claimed that these group of people reluctant to mingle with the local communities and prefer to live exclusively on their own. This scenario will eventually weaken the solidarity of the community and detach the previous close-knit neighbourhood, which has become the community's identity for so long. This is also seen as an identity disruption by the respondents.

Second are the community whom were moved from the area to be developed. There were at least two major communities involve in this scenario, the fishing and the estate communities. Both have been re-located into new settlement to enable their previous settlement area to be developed. These communities obviously practiced certain traditional norms and values which were passed over through generations in their previous settlement for example, the norm to love and respect the nature which becomes impossible to be realized in their high rise, cluttered, semi-urban new settlements. The changes in social and physical settings would leave the communities of no choice but to omit some of their long lived norms and values. To the respondents, this is also a form of identity disruption.

Another scenario was the re-construction of traditional villages. Some of traditional villages in Sepang were slowly transformed into systematic housing area to accommodate rising demands from surrounding developing areas. This action is seen by the respondents as irrational and ridiculous. These traditional villages should otherwise be conserved and valued, not only for their physical features but more important was the history and identity embedded inside them. The respondents however agreed for these traditional landscapes to be upgraded provided the originality of its structures is conserved. If this measure is not taken, the traditional landscapes will eventually disappear from this area, and so does its identity.

Fourth is the integrity of the personals involved in development. The respondents saw integrity as the strongest pillar of identity. They claimed that there were many incidents of power abused among development personals including corruption and malpractice. The respondents strongly believed that development negative consequences mostly resulted from the lack of integrity of personals involved. They insist development personals especially the government officers to be more ethical and honest, and comprehend their roles adequately. In order to increase the integrity of the governance, it should be governed in a more transparent manner. To the respondents, the integrity of the governance and its governors is the distinctive quality of identity.

Wrapping up the discussion on identity, the respondents stressed out the importance of solid citizenship and unity in mitigating above problems. They ruled out that good citizen posse's good will and strength to safeguard the identity and sovereignty of the nation. Moreover, a good citizen whom can be seen as a solitary strength will 
be able to steer the community towards unity, and forming the collective strength. Unfortunately, the respondents claimed that the present formal education systems are lack of appropriate elements to cultivate good citizenship when they are focussing to science and technology from the very beginning. They reckon that the elements of citizenship to be introduced and nurtured during the early years (primary and secondary school) while the science and technology aspects came in later, only after the students has a firm grasp of their identity. This will reassure that the development processes are in good hand in years to come.

\subsection{Peace}

The main concern of this theme is safety. This issue is again related to the foreigners; students and workers. The students specifically, frequently reported involved in alcohol-related incidents like reckless driving, street fighting, vandalism and sexual misconduct. The workers on the other hand are observed to be involved more in burglary and robbery. The respondents claimed that many workers remain to reside in this country despite their expired working pass. It was more difficult to monitor these peoples due to their illegal residence. Some of local employers have taken advantage on these people by paying them inadequately resulting in deprivation which later ignite their unlawful behaviour. Majority of the respondents obviously worried of their safety because they felt that the situation is becoming out of control.

\subsection{Freedom}

There are rising cautions among the respondents of their freedom throughout the development process. They raised three issues related to the exercise of freedom i.e. right and privilege, participation and politics.

Obviously, right and privilege is the core attribute of freedom. In this study, the respondents claimed that their right and privilege have systematically being denied by the developers. Two major scenarios reflected this issue are the development of Pantai Bagan Lalang and Sepang Gold Coast. In both projects, local people's lands are reclaimed and sold to the developers, with or without consents of the owners. Under this procurement, the land that was previously reserved for native can now be occupied by the non-native, outsiders and foreigners. The owner of the land will be compensated either by monetary or land substitution method. The respondents claimed that the monetary reward is much lower than the actual market price which they seen as manipulation of their right. In the case of land substitution, the land owners are entangled in the complicated ownership establishment. According to the respondents, the owners are given TLO (Temporary Land Ownership) lands which can be converted into permanent under specific scheme. However, they claimed that the cost of premium in the conversion process is very high and unaffordable. This is again seen as a manipulation of right of the local people.

The respondents claimed that the development in Pantai Bagan Lalang and Sepang Gold Coast, demonstrated the scenario of privilege denial. According to the respondents, both developments implicate the privilege of local people in three ways; the privilege to retain their chosen way of life, the privilege to decide on what or how to develop their own land and the privilege to benefit from the process.

Pantai Bagan Lalang was formerly served as the traditional landing point for local fishermen. In recent years, the beach has been developed and transformed into moderate resort facilities until recently, it has been commercially developed into a more sophisticated recreational facilities to accommodate the surrounding developments especially Sepang Gold Coast. Sepang Gold Coast is a systematic, elite housing estate covering approximately 600 hectares land area. To finance this expensive project, outside and foreign investors are eagerly persuaded while the surrounding facilities upgraded accordingly. Sound and expensive business infrastructures are developed to cater the high scale demand and the open market system is practiced to induce the financial climate. Obviously, local people can't afford to involve in the costly operations and to survive the rising cost of living. The respondents claimed that the whole process resulted in local people losing control of their homeland, marginalized in the development process and finally become inferior to their successors, the outsiders and foreigners. Therefore the respondents brought out to the fore questions concerning for whom the development being carried? Ruling out the issue of right and privilege, the respondents stressed out that development should first cater the well-being of local people before providing an environment that is conducive to the outsiders and foreigners.

Other than right and privilege, participation is also a powerful expression of freedom. There was frustration expressed by the respondents for not being able to voice out their view and opinion towards the development as they believe that public participation is vital in gearing a meaningful development. Apparently, the respondents do not aware that there are numbers of ways for them to channel their views including public forums organized by the government which are held few months apart. However, even after being informed of such programs, the respondents are skeptics of the opinions of being fairly considered by the organizer. 
Nevertheless, the respondents also admitted that public sometimes is unsupportive in term of participation. They claimed that some people refused to be taxed by the municipal council and willing to be left out from the master development plan just to save some money. The respondents believed that this irrational decision would drag non-dismissible damage to development process. Besides being selfish, some other people displayed ignorance and unthankful attitude. The government has allocates certain amount of budget to develop business facilities to be operated by local people. However, this privilege has been misuse by most of the alleged owners by renting it out to the foreigners instead of operating it on their own. Both scenarios displayed public's inappropriate attitude towards development in term of participation. Aware with the presumed barrier impose by developers, the respondents saw these inappropriate attitudes demonstrate by public reduce effective participation significantly.

Many approve that freedom and politic are influential to each other. In this study, politic become one of the main concern in the theme of freedom after a major political transition during recent general election has taken place. After the election, the opponents' members won majority of the state assembly seats which allow them to become the new state governances. Under the new government, a lot of policies have been reshuffled, including those in terms of development. The respondents claim that these reformations were not embraced by people in charge. They claimed that the government officers who served former governments practice discrimination due to political disparity. Apparently, this practice will enlarge the existing gap between opposed party members and weaken the solidarity needed to pursue development. The government officers should otherwise, be more ethical in fulfilling their responsibilities towards serving the public regardless of their different political stands.

Similar scenarios are also evident among public. The political disparity has diverged public support to the new leadership which disengage certain group of people from participating in the development process. The disunity among public is seen by the respondents as a major threat in development and they insisted the public to dismiss being skeptical towards each other and concentrate on working their way to pursue the aspired well-being.

\subsection{Environment}

In this study, environment issues have also been raised even though not as prominent as identity and freedom. Previous research shown that environment has being studied in multiple aspects including its aesthetical, historical or economic values, services or product, pollution and degradation, and currently, sustainability. Environmental issues highlighted by the respondents in this study are pollution and environmental disaster resulted from improper development. There are two pollution raised by the respondents i.e. water pollution resulted from construction waste and pig farming; and air pollution due to quarry operation. Another form of pollution i.e. noise pollution has not been mentioned by any of the respondents.

There are two major sources of water pollution in this area, the construction waste and pig farming discharge. Like other developing area, Sepang is exposed to devastating rising amount of construction waste. The respondents claim that the waste is not properly managed with most of it is dumped into surrounding waters. This irresponsible action not only will pollute the water but it could also be life threatening to living organisms as well. Indirectly, this condition will affect communities who depend on this ecosystem for living such as the fishing communities.

Another significant source of water pollution is pig farming discharge. Sepang was once became a major producer of pig livestock in Selangor, Malaysia, and contributed much towards the economic development of this area. However, it was also the major polluter towards the surrounding water body. The pollution was resulted from direct disposal of discharge into drains or stream interconnected with the river system in this area. According to the respondents, the farms were operated in Sepang for number of years until recently moved to adjacent district. However, the previously discharge disposal remain in the water body while the new discharge still reach this area through connecting streams and rivers. Apart from degraded water quality, this pollution also produced visual and odor problems. The affected water is dark in color and smelly, which disturbed the public deeply. The respondents insist that strict regulations and surveillance imposed on the farming activities to mitigate such pollution.

The second form of pollution raised by the respondents is the atmospheric pollution resulted from the quarry operations. Quarry operations have become intensified due to rising demand from the construction sectors. Together with the increasing amount of suspended particulate matter from growing construction areas, the atmospheric pollution in this area is getting worse. The pollution is not confined in the quarry only but also is transported to other area. The respondents claim that this situation affects their well-being very much and they expect measures taken to inhibit further deterioration.

Apart from pollution, the respondents also highlighted another environmental issue that is related to development i.e. environmental disaster. Two major form of environmental disaster in this area are flash flood and landslides. 
The respondents claim that the incidents of flash flood and landslides becoming more frequent lately with expanding devastating effect. They believe the flash flood resulted from the increasing built area and the shallower of river. Increasing built area leave lesser natural bed to absorb running water. The increasing built areas also reduce the amount of vegetative to hold the soil which resulted in the shallower of the river. The shallower rivers become incapable to retain the water in its capacity and causing the flood. In the incidents of land-slides, the respondents put the blame to the development of individual lots. They claim that these lots have been developed recklessly and disturbed sediment stability which lead to the incidents of landslides. The respondents urge the owner of these lots to be more considerate when developing their lots.

Overall, it is evident that the respondents regard environment very important in pursuing their well-being even though none of them relate it to health aspect. The respondents saw these environmental problems as consequences of improper development. They believed that if the development is properly managed, it will not bring adverse effect to the environment and people. To them, every development plan should anticipate every possibilities and implications and designed to minimize defect and destruction along the way.

\subsection{Development}

Majority of the respondents perceived that present development disregard human development of local people. Again, in reference to the moved community, the respondents claimed that the moved communities were left unattended without proper training to empower their survival in the new environment. The government should otherwise provide proper and systematic training and planning to facilitate the community to embrace new ways of income-generating options. The moved community domineered by fishing and estate communities should be continuously and consistently trained to new skills to substitute their previous skill as fishermen and estate workers. One of the respondents suggested small medium industries (SMIs) as one effective approach to undertake this problem. He believed that SMIs not only provide career opportunities to the new settlers but also to school drop-out since they required only minimal skill and knowledge to operate. The respondents claimed that there were a few training courses offered to the new settlers but unfortunately, follow-up programs are still lacking.

Along with the suggestion of SMI, the respondents urged developers to optimize the existing sophisticated facilities like KLIA and Cyberjaya smart city to boost economic sectors and enhancing human development. Major flaws of development that is raised by the respondents were the mega projects which benefited a few while degraded many. There were considerable worries about increases in development and the subsequent loss of public areas. The respondents argue that the large scale development left too little public area to accommodate public facilities like schools, playgrounds, worship building and cemetery. Developers should anticipate the consequences of development such as rising in population which demand more facilities, and address these issues accordingly.

In conclusion, the respondents feel that present development is only focusing on material benefit and disregard human and environmental well-being. However they still believed that development was relevant to their pursuit of well-being provided adequate potential impact is taken into account. Thorough impact assessment should be conducted prior to the process including the social aspect. Majority of the respondents ruled out that the synchronization between physical and moral and ethical aspects are vital in development. Development process should at all time and circumstances ethically planned and conducted, and vigorously monitored.

\section{Discussion}

There are five themes emerged from the thematic analysis conducted on the data namely identity, peace, freedom, environment and development. Even though the themes appear to be distinctive from each other, they are also interrelated by the issues featured under each theme (Figure 2).

Firstly, the theme of identity is linked to the theme of peace by the issues of foreigners. Both themes portray foreigners or foreign influences as threat to the well-being. The theme of identity also link to the theme of freedom, environment and development. It is linked to freedom and environment by the issues of outsiders. Indirectly, the outsiders' issues that were featured under the theme of identity affect the theme of freedom and environment as well. The theme of freedom partly related to outsiders because the process of developing and upgrading the present environment to attract outside prospect investors degraded the right and privilege of local people in several ways including land ownership and cost of living. In term of environment, the overwhelming attention towards the needs and demand of the outsiders also resulted in several environmental problems. To upgrade the facilities in this area, the construction activities are heightening tremendously which left subsequent amount of waste. These wastes pollute the environment of this area especially the water body. The fourth link of identity is to the theme of development. It is linked by the issues of negligence towards moved communities. 
Under the theme of identity, the issue of negligence is towards their intention to practice their norms while under the theme of development; the act of negligence is towards their jobless situation.

The theme of development could also be linked to the theme of environment and freedom. The issue that linked development to environment is again the pollution resulted from construction activities. As elaborated above, the construction activities are progressing tremendously due to increasing demand from the developers. These activities in turn produce tonnes of construction waste. This kind of waste is difficult and costly to manage therefore illegal dumping was opted in most cases. The increasing amount of illegally dumped construction waste obviously degrades the environment quality significantly. As of the link of development and freedom, the issue is directly related to local people right and privilege. Inadequacy of public amenities under this theme reflects the unprivileged circumstances of the local people.

The linkage among themes indicates that the issues concerned by the respondents are interrelated. The interrelations provide the framework of how the respondents' development values constructed and circulated. The theme of identity can be linked to every other theme. This will suggests identity as the core attribute of the respondents' development values.

Further analysis on the data revealed seven needs components namely subsistence, protection, affection, participation, freedom, creativity and identity. Two other components listed by Max-Neef et al i.e. understanding and leisure was not evident in this study. The need of understanding is described by Max-Neef et al as the ability to develop critical capacity, curiosity and intuition to empower individuals to analyze study, meditate or investigate their surrounding. Throughout the analysis, we did not find any remark purporting to this need component implying that understanding is not considered as a need by the respondents.

Another missing component of need in this study was leisure. The need of leisure comprises the element of imagination, tranquillity and spontaneity which allow individuals to acquire the peace of mind and have fun. Similar to the need of understanding, the need of leisure did not occur throughout the discussions. The reason might be that even though Sepang is developing rapidly, the green area of this district is still abundant despite hectic activity of land clearance. This is because most of the mega projects develop beautiful landscapes which provide element of leisure as effective as the nature. Therefore, leisure is not perceived being in threat and this might be the reason it is not considered as need by the respondents.

As mentioned earlier, the other seven needs components from Max-Neef et al. list of fundamental needs present in this study. Some of the components can be discreetly connected to the key values i.e. the needs of identity to the key value identity, the needs of protection to the key value environment, and the needs of subsistence to the key value development. There is also evident that the needs of protection presents in all key values. The other needs components however are not directly related to the key values but can be included submissively under specific values i.e. the needs of affection to the key value development, the need of participation to the key value freedom and the need of creativity to the key value development.

The needs of protection which present under each key value indicate the public perception of insecurity in the present development process. According to Max-Neef et al. (1991) matrix of needs, protection is associated with care, adaptability and autonomy towards social components such as safety, health and work. In this study, care, adaptability and autonomy are rectifying as requirements to achieve well-being i.e. care for the identity, peace and environment; adaptable to development and; autonomy to exercise the freedom. Therefore, the need of protection is evident as the most important need to be satiated to achieve well-being.

The need of affection, as elaborated by Max-Neef et al., related to respect, sense of humour, generosity and sensuality demonstrated in the relationship among family, friends and neighbours. In this study, the need of affection is seen very significant to overcome the problems related to development of individual lot. They seen the problems like landslides or flash flood due to inadvertent development of individual lot are increasing in recent years. This kind of development does not have to comply with development act which aggravate the matters. Therefore, the public in Sepang urges the community to be more affectionate to the well-being of their neighbours when developing their lot.

The needs of subsistence and creation are evident under the key value of development. According to Max-Neef et al., subsistence is prerequisite for mental and physical health. Food, shelter and work are among the basic necessities covered by subsistence. The definition of subsistence given by Max-Neef et al. is similar to the basic needs definition by Maslow (1970). Many researches agreed that both compromise the needs that proposed by Brundtland (1987). The need of subsistence in this study is specifically address the issue regarding sources of income. The public in Sepang feel that the current development process jeopardized their sources of incomes in several ways and this affect their well-being badly. This perception leads the public to see subsistence as one of 
the vital need in development. The need of creation in this study is also linked to the key value development. Among the elements listed by Max-Neef et al. under this need are imagination, boldness, inventiveness and curiosity. As these elements are requirements to invent, build, design, work and compose, creativity is associated with career and job development. In this study, creation has only been mentioned by the urban community. This might be related to their larger exposure to the current issues in development especially economy compare to the rural community. Along with the need of subsistence, creation is seen by the public in Sepang as vital need to allow survival and well-being.

The need of identity in this study is depicted by the issues of culture and norm, and integrity. Apparently, this need construct the key value of identity. The respondents' statements reveal that they value identity highly because it resembles their belief and principles, and also their honour and integrity. The perceived harmful intrusions of foreigners and outsiders encourage the public to consider identity as one of the need in development. Apart from outside intervention, the issue of integrity which enshrines from the malpractice and power abused of the developers also seen as a flaw to identity. The public blame the corrupt developers for the most of faulty consequences of the current development and they believe that reinforce of identity is needed to steer the development back on the right track.

The need of freedom is defined by Max-Neef et al. as the ability to realize autonomy, passion, self-esteem and open-mindedness. In this study, the public of Sepang from the rural areas perceived that their freedom to express their inner and out-self deprived by the developers. They claimed that their rights are denied, their views are dismissed and their consents are waived. These perceptions lead the public to see freedom as development need. Apart from the need of freedom, the need of participation is also indirectly related to the key value freedom. Participation is referred to the act of cooperation, dissention or opinion expression in response to the receptiveness and dedication of the individuals. In this study, the public recognize the importance of effective participation in pursue of their well-being in development. As they are claiming that participation in present development is lacking, public in Sepang believe that participation is highly needed.

Majority of the statements made by the respondents highlight the defaults of development. They perceived that the development decrease their well-being as its goals and mechanisms degenerate their identity, peace, freedom and environment, and defeat the presuppose purpose of development. These perceptions encourage the respondents to portray subsistence, protection, affection, participation, freedom, creativity and identity as the needs to overcome the threat and be able to achieve their well-being throughout the development process. Their perceptions of ill-being may be explained as below.

Previous researches noted that people are more likely to experience positive well-being when their needs are satiated and their values are fulfilled (Sagiv \& Schwartz, 2000; Bilsky \& Schwartz, 1994; Triandis, 1990; Furham \& Bochner, 1986; Kohn \& Schooler, 1983; Segall, 1979; Feather, 1975). When the situational context blocks people's realization of their values, they are likely to experience negative well-being. According to Sagiv and Schwartz (2000), there are three complementary, yet conceptually distinct mechanisms through which value congruence between person and environment may influence the sense of well-being; environmental affordance, social sanctions and internal conflict.

Social and physical environments offer a set of opportunities for and constraints against needs satiation (Gibson, 1979). These opportunities may not be congruent with individuals' needs and plans and it will likely produce negative well-being (Pervin, 1992). In some environments, there are constraints which deprived the needs or values aspired by people and this could also inhibit the positive well-being. In this study, the opportunities provided by development seem to be incongruent with the prevailing public values. The transformation of Sepang from traditional and agriculture setting into a modern, commercial area which provides functional utilities and action possibilities are perceived to deprive the actual needs more than to improve. Apparently, there are conflicts between the values held by the developers and public. Such conflicts have been described by Schwartz (1992) through an integrated structure of values. According to Schwartz, the integrated structure of values can be summarized into two orthogonal dimensions; the openness to change dimension opposing the conservative dimension and the self-transcendence dimension opposing the self-enhancement dimension. In this study, public values can be categorized into the conservation dimension consists of values like protection and identity. In contrast, the developers promote values that support advancement and improvisation which fit the criteria of openness to change dimension. The conflicts between the values resulted in negative well-being perception to the public.

A second way to view environments is as sets of expectations, backed by implicit or explicit sanctions (Getzels, 1969). People who reject the prevailing normative definitions, because these definitions oppose their own values 
may be ignored, ostracized, and sanctioned or punished (Holland \& Gottfredson, 1976 which would undermine their sense of well-being. People who share the prevailing normative definitions may benefit and supported, and this may enhance their sense of well-being. In development context, the 'prevailing normative definitions' are most likely created or shaped by the developers or government. In this study, the public that seem to behold opposing values is facing multiple social sanctions are in the form of denial, abandonment and ignorance. Those sanctions are pronounce in every theme except peace. The expressions indicating the need of protection under every theme also strengthen the respondents' sanction perception.

Thirdly, one's sense of well-being may be undermined by conflict between values acquired earlier and values whose internalization is advocated in a new environment (Schwartz, 1992; Tetlock, 1986). Such conflict has been shown to undermine subjective well-being (Oles, 1991). Similar to the theory of social sanction, the internal conflict theory could possibly explain the finding of this study. Apparently, the transformation of Sepang is not fully embraced by majority of the public whom preferred the previous social setting. This would likely create the tension between the new values imposed by the developers and the values that the public like to remain. It is also witnessed that the conflict does occur among the public as well. Individual lot development is one example of this. These conflicts witnessed under freedom (public vs. developers) and development (public vs. developers; public vs. public) themes. Again as in the orthogonal dimensions of values Schwartz (1992) suggested earlier, the values in conflict are most likely the conservation and the openness to change dimension when public and developers involved while self transcendence and self enhancement dimension opposes is more likely occurred in the public internal conflicts.

Supporting this explanation, we like to embrace the values adaptation studies by Kohn and Schooler (1983) and Schwartz and Bardi (1997). Both studies have demonstrated how people adapt their value priorities to their surrounding conditions. It is witnessed that values that represent deficiency needs (e.g. safety) are especially important to those who are unable to pursue well-being in the current surroundings. Conformity, security and power values were classified as representing deficiency needs (Bilsky \& Schwartz, 1994). Giving priority to these values is therefore more likely among people who feel unsafe, lacking in control over their lives, and threatened in their relation with others, feelings that give rise to a negative sense of well-being. In this study, it is obvious that the respondents perceived their negative well-being resulted from deprivation of their needs. Six of the needs identified can be associated to above three values; the needs of subsistence and protection with the value of security; the needs of affection and identity with the value of conformity, and; the needs of participation, identity and freedom with the value of power. Identity in the value of conformity regarding to retaining the custom and tradition while in the value of power, identity marks the need in regaining the rights and privileges. The need of creativity in this study may be connected to the value of security for it concerns in job creation but the term creativity itself is always aspired more positive than negative, therefore in this study, creativity is not considered as a deficiency need. The analysis shows that the respondents in this study acquire six deficient needs which indicate their negative state of well-being.

Similar findings in relation to the values adaptation studies have been demonstrated by Bilsky and Schwartz (1994) through the causal influence theory. According to the theory, the values priorities may be influenced by the sense of individual well-being. People who are happy and satisfied with their lives may be more likely to have emotional resources to pursue autonomy (self-direction), emphasize tolerance (universalism), and focus on the welfare of others (benevolence) for example. In contrast, people who are unhappy and dissatisfied may be occupied more with their own problems and lack resources to pursue such 'healthy' values. Instead, they may pursue values like security or power, whose realization promises relief from anxiety and satisfaction of survival needs (Bilsky \& Schwartz, 1994).

\section{Conclusion}

The public in Sepang has demonstrated considerable concern over the issues in relation to development in their area. Despite assumption on public's limited capabilities in understanding those issues, this study shown that the public in Sepang possess the abilities to recognize their vital needs and values in pursue of sustainable living. Even though their knowledge in sustainable development is minimal, their aspirations for the development to safeguard the identity, environment, freedom and peace reflected the essence of sustainable development. Planners and developers should aware that the perception that public views on development as emotional and irrational is not true. Instead they should work together on their values to promote sustainable development. Apparently, they should learn the values people hold rather than assume that it is known, and they should never underestimate the diversity of values and their importance to people. In present, many policy disagreements resulted from confusing presupposition about public values that have not been clearly illuminated. 


\section{References}

Adams, W.M. (1990). Green Development: Environment and Sustainability in the Third World. London: Routledge.

Aronson, J. (1994). A pragmatic view of thematic analysis. The Qualitative Report. Available: [Online]: http://www.nova.edu/ssss/QR/BackIssues/QR2-1/aronson.html (July 16, 2007)

Bilsky, W., \& Schwartz, S.H. (1994). Values and personality. European Journal of Personality, 8, 163-181.

Boyatzis, R.E. (1998). Transforming Qualitative Information: Thematic Analysis and Code Development. London: Sage Publications.

Dolan, P., Peasgood, T., \& White, M. (2006). Research on the relationship between well-being and sustainable development. Available: [Online]:

http://www.defra.gov.uk/science/project data/DocumentLibrary/SD12006/SD12006 4019 FRP.pdf (January 22, 2008)

Feather, N.T. (1975). Values in education and society. New York: Free Press.

Furham, A., \& Bochner, S. (1986). Culture shock: Psychological reaction to unfamiliar environments. London: Methuen.

Getzels, J.W. (1969). A social psychology of education. In G. Lindsey and E. Aronson (Eds.), The handbook of social psychology (vol 5). Reading, MA: Addison-Wesley.

Holland, J.L. (1985). Making vocational choices: A theory of careers. Englewood Cliffs, NJ: Prentice-Hall.

Holland, J.L. \& Gottfredson, G.D. (1976). Using a typology of persons and environments to explain careers: Some extensions and clarifications. The Counselling Psychologist, 6, 20-29.

Kohn, M., \& Schooler, C. (1983). Work and Personality. Norwood, NJ: Ablex.

Maslow, A.H. (1970). Motivation and Personality. New York: Harper \& Row.

Max-Neef, M.A., Elizard, A., \& Hopehayn, M. (1991). Development and Human Needs: Human Scale Development: conception, application and further reflections (pp.13-54). New York: The Apex Press.

Milbrath, L.W. (1984). A proposed value structure for a sustainable society. Environmentalist, 4, 113-124.

National Research Council, Policy Division, Board on Sustainable Development. (1999). Our Common Journey: A Transition toward Sustainability. Washington DC: National Academy Press.

O'Brien, E.A. (2005). Publics and woodlands in England: Well-being, local identity, social learning, conflict and management. Forestry, 78(4), 321-336.

O’Brien, M., \& Guerrier, Y. (1995). Values and the environment: An introduction. In G.Yvonne, A. Nicholas, C. Jonathan, \& O.B. Martin (Eds.), Values and the Environment: A Social Science Perspective (pp.xiii-xvii). Chichester: Wiley.

Oles, P.K. (1991). Value crisis: Measurement and personality correlates. Polish Psychological Bulletin, 22, 53-62.

O’Neill, J. (2001). Representing people, representing nature, representing the world. Environ. Planning C: Government Policy, 19, 483-500.

Pervin, L.A. (1992). Traversing the individual-environment landscape: A personal odyssey. In W.B. Walsh, K.H. Craik \& R.H. Price (Eds.), Person-environment psychology: Models and perspectives (pp.71-88). Hillsdale, NJ: Erlbaum.

Prince-Gibson, E., \& Schwartz, S.H. (1998). Value priorities and gender. Social Psychology Quarterly, 61(1), 49-67.

Rokeach, M. (1973). The nature of human values. New York: Free Press.

Sagiv, L \& Schwartz, S.H. (2000). Value priorities and subjective well-being: Direct relations and congruity effects. European Journal of Social Psychology, 30 (2), 177-198.

Schneider, B. (1987). $\mathrm{E}=\mathrm{f}(\mathrm{P}, \mathrm{B})$ : The road to a radical approach to person-environment fit. Journal of Vocational Behavior, 31, 353-361. 
Schwartz, S.H. (1992). Universals in the content and structure of values: Theoretical advances and empirical tests in 20 countries. In M.P. Zanna (Ed.), Advances in experimental social psychology (vol 25, pp.1-65). San Diego, CA: Academic Press.

Schwartz, S.H., \& Bardi, A. (1997). Influences of adaptation to communist rule on value priorities in Eastern Europe. Political Psychology, 18(2), 385-410.

Schwartz, S.H., \& Sagiv, L. (1995). Identifying culture-specifics in the content and structure of values. Journal of Cross-cultural Psychology, 26(1), 92-116.

Segall, M.H. (1979). Cross-cultural psychology: Human behavior in global perspective. Monterey, CA: Brooks/Cole.

Tesch, R. (1990). Qualitative Research: Analysis, Types and Software tools. Hampshire: The Falmer Press.

Tetlock, P.E. (1986). A value pluralism model of ideological reasoning. Journal of Personality and Social Psychology, 50, 819-827.

The Johannesburg Declaration on Sustainable Development. (2002). Available: [Online]: http://www.housing.gov.za/content/legislation_policies/johannesburg.html (June 19, 2008)

Triandis, H.C. (1990). Cross-cultural studies of individualism and collectivism. In J. Berman (Ed.), Nebraska Symposium on Motivation, 1989 (pp.41-133). Lincoln, NB: University of Nebraska Press.

Walsh, W.B., \& Holland, J.L. (1992). A theory of personality types and work environments. In W.B. Walsh, K.H. Craik, \& R.H. Price (Eds.), Person-environment psychology: Models and perspectives. Hillsdale, NJ: Erlbaum.

Williams, M. \& May, T. (1996). Introduction to the Philosophy of Social Research. London: UCL Press.

World Commission on Environment and Development (WCED). (1987). Our Common Future. New York: Oxford University Press.

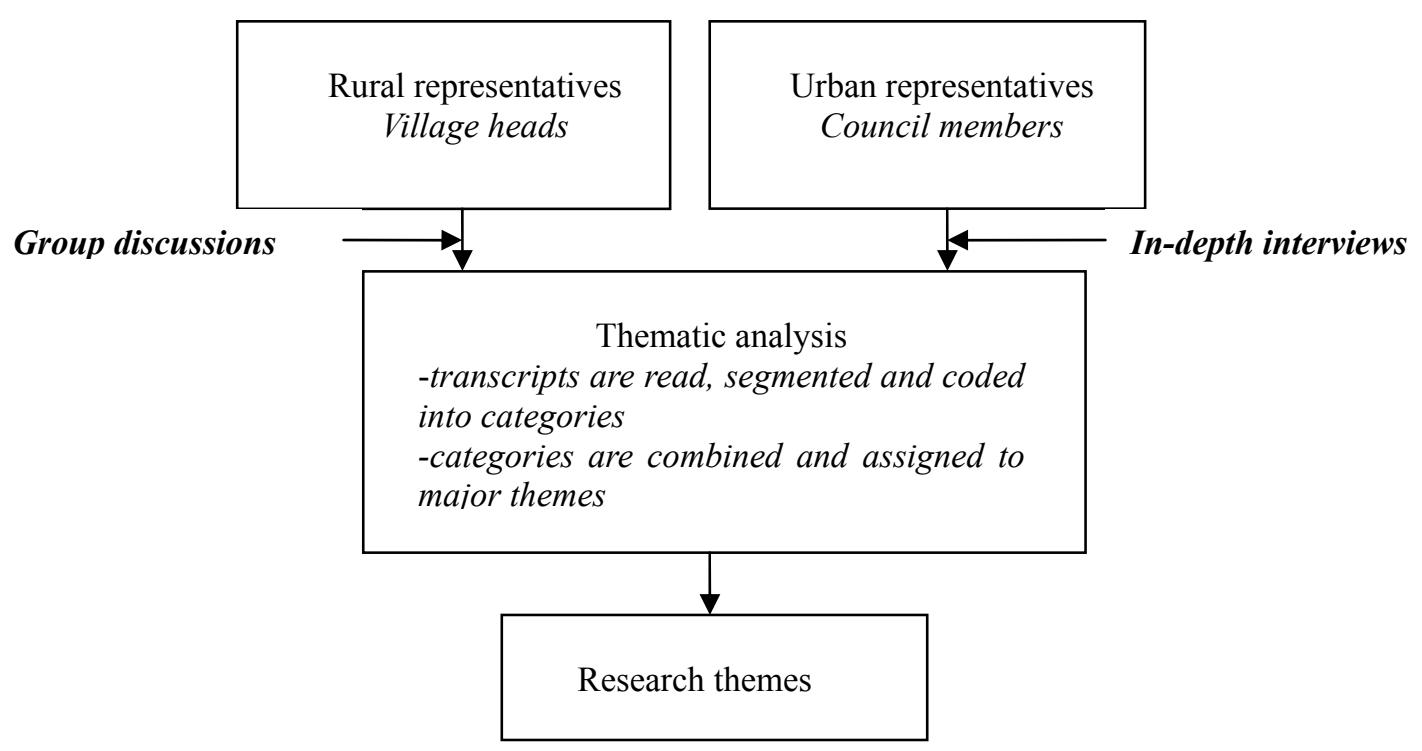

Figure 1. Research Methodology Flowchart 


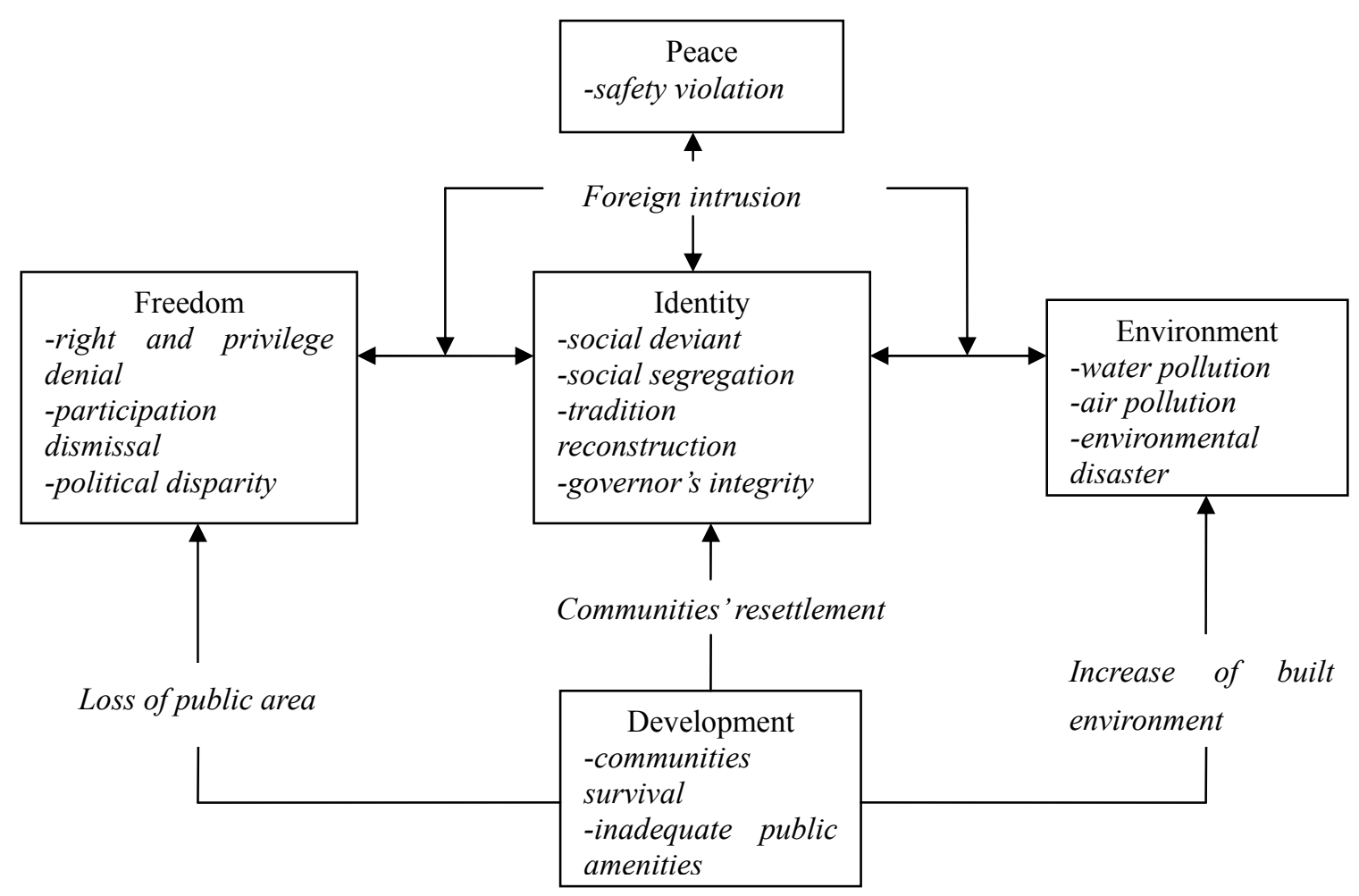

Figure 2. Themes of the research 